Selçuk Üniversitesi

İktisadi ve İdari Bilimler Fakültesi

Sosyal Ekonomik Araştırmalar Dergisi

(The Journal of Social Economic Research)

ISSN: 2148 - 3043 / Nisan 2016 / Y11: 16 / Say1: 31

\title{
EFQM MÜKEMMELLİK MODELİ VE MOBILYYA SEKTÖRÜNE YÖNELİK BİR UYGULAMA
}

\section{Okut. Dr. Sevgi SÜMERLİ SARIGÜL}

\author{
Yrd. Doç. Dr. Burcu ORALHAN
}

\section{ÖZET}

\begin{abstract}
İşletmelerin, günden güne değişen ve gelişen dünya ekonomisine ayak uydurabilmeleri güçleşmektedir. $\mathrm{Bu}$ sebeple işletmeler performans iyileştirme ve verimlilik arttırma çalışmalarına yoğunlaşmıştır. İyileştirme çalışmalarında süreklilik sağlanmadığı takdirde başarısızlığın kaçınılmaz olduğu bilinmektedir. Sürekliliğin sağlanabilmesi için ise işletmelerin öz değerlendirmelerini yapmaları gerekmektedir. Öz değerlendirme modellerinden biri olan EFQM mükemmellik modeli toplam kalite yönetiminin yaklaşımları olan "sıfır hata" ve "mükemmellik" kavramlarının birleşmesiyle ortaya çıkmıştır. Bu model, işletmelerin mevcut yapısının ve faaliyetlerinin sonuçlarının sistematik bir şekilde incelenmesinin sağlanmasında, güçlü ve zayıf yanlarını tespit edilebilmesinde yardımcı olan bir öz değerlendirme aracıdır. Bu model liderlik, çalışanlar, politika ve strateji, işbirlikleri ve kaynaklar, süreçler olmak üzere beş girdi, çalışanlarla ilgili sonuçlar, müşterilerle ilgili sonuçlar ve toplumla ilgili sonuçlar ve temel iş çıktıları olmak üzere dört sonuç kriterinden oluşarak sistemi bir bütün halinde değerlendirir. Ortaya konan çalışmaların, hedefleri ne kadar iyileştirdiği izlenirken PUKÖ döngüsünden faydalanılır. Bu döngü planlama, uygulama, kontrol etme ve gerektiğinde önlem alarak yeniden planlama aşamasına dönerek sürekli iyileştirmenin sağlanmasında önemli rol oynamaktadır.
\end{abstract}

Dünyada birçok farklı ülkede ve farklı sektörlerde uygulanan öz değerlendirme aracı olan EFQM modeli bu çalışmada Kayseri'de faaliyet gösteren bir mobilya işletmesinde uygulanmıştır. Yönetim kurulu, yöneticiler ve beyaz yaka çalışanları kapsayan bir anket çalışması yapılmıştır. Dinamik bir değerlendirme sistemi olan analizin RADAR yaklaşımı ile puanlama yöntemi sonucunda işletmenin 396 puan aldığı ve temel performans göstergeleri, süreçler ve müşterilerle ilgili sonuçlarda yüksek puan alındığı görülmüştür. SWOT analizi yapılan işletmede zayıf yönler, iyileştirmeye açık alanlara göre iyileştirme ve geliştirme projeleri önerilmiştir. Belirlenen projeler ile firmanın EFQM seviyesinin artırılması amaçlanmıştır. Bu amaçla 2015-2017 yılları arasında etki ve yapılabilirlik durumuna önerilen sistemlerin kurulması hedeflenmiştir. $\mathrm{Bu}$ iyileştirmeler yapıldığı takdirde 2017 yılsonunda yeniden EFQM hesaplaması yapılarak firmada yapılan iyileşmenin EFQM skoruna yansıması izlenecektir. Böylece hedefler doğrultusunda ne kadar ilerleme olduğu ve uygulama sonucu elde edilen yararlara ilişkin değerlendirmelere yapılabilecektir. Yapılan bu çalı̧̧manın öncelikle mobilya olmak üzere tüm sektörde EFQM mükemmellik modelinin bir uygulama örneği olması amaçlanmıştır. 
Anahtar Kelimeler: Mükemmellik Modeli, EFQM, SWOT Analizi, RADAR Mantığı, Mobilya Sektörü, PUKÖ Döngüsü

Çalışmanın Türü: Araştırma

\section{EFQM EXCELLENCE MODEL AND AN APPLICATION IN THE FURNITURE SECTOR \\ SUMMARY}

Businesses are changing day by day and difficult to be able to keep up with the evolving world economy. This is why the company has focused on improving the performance and productivity improvement efforts. If the failure is not provided continuity in the improvement work, it is known to be inevitable. In order to ensure the continuity of the business it is required to make the self-assessment. EFQM excellence model, one of the self-assessment models of total quality management approach, "zero error" and "perfection", has appeared with the merger of the concepts. This model business in a systematic way in ensuring the results of the examination of existing structures and activities, and is a powerful self-assessment tool that helps to correctly identify their weaknesses. This model may consist five inputs which are leadership, employees, policy and strategy, partnerships and resources, processes and also may consist the results related to the employees and it evaluates the customer with the relevant conclusions and society about the results and key business outcomes of four results criteria so that the system may be evaluated as whole. Setting out the study objectives, it is benefited from improving how it monitors the PDCA cycle. This cycle of planning, implementation and control plays an important role in.

In this study, EFQM model is a self-assessment tool applied in many different countries in the world and has been implemented in different sectors of the furniture business in Kayseri. The board of directors, executives have conducted a survey covering white-collar workers. The analysis of the dynamics of the business as a result of an evaluation system approach RADAR scoring with 396 points and key performance indicators processes, and related points have been shown to the customers. Weaknesses in the business made SWOT analysis, improvement and development projects and areas open to the improvement have been proposed.. EFQM is aimed to increase the level determined by the company's projects. For this purpose, effects between the years 20152017 and it is also aimed to establish the feasibility of the proposed system status. The reflections of the improvements to EFQM score will be monitored by recalculating EFQM if these improvements can be achieved. Thus, the evaluations will be able to be made on the benefits gained through the results of the applications and how much improvement achieved. . This study was primarily intended to be an application made of the EFQM excellence model example in all sectors, especially furniture.

Keywords: Excellence Model, EFQM, SWOT Analysis, RADAR Logic, Furniture Sector, PDCA Cycle

The type of research : Research 


\section{GíRIŞ}

Etkili bir yönetim gerçekleştirilebilmek için, faaliyetlerin ve sonuçlarının etkin ve doğru bir şekilde ölçülmesi gerekmektedir. Hedeflenen mükemmel sistemin oluşturulabilmesi için ölçüm sisteminin ihtiyaçlar doğrultusunda geliştirilmesi ve uygulamaya aktarılabilmesi önem teşkil etmektedir. İşletmelerde süreklilik arz eden faaliyetlerin kontrolünün sağlanması ve iyileştirme, geliştirme yapılması gereken alanların tespit edilmesi için öz değerlendirme yapması şarttır. Öz değerlendirme işletmenin performansını göz önüne sermektedir (Kalder,2010).

Kısa, orta ve uzun süreli hedefler üst yönetimler tarafindan ortaya konulurken işletmelerin iç ve dış müşterileri, paydaşları, süreçleri ve çalışanları daha önce belirlenen vizyon, misyon ve politikaları çerçevesinde oluşturulur. İşletmelerin faaliyet alanlarının tamamını göz önüne alarak yapmış oldukları bu öz değerlendirme esnasında süreçlerin doğru ve tam bir şekilde tanımlanması önem arz etmektedir. Yapılan öz değerlendirme çalışması, olması gereken veya hedeflenen duruma ne kadar yakın olduğunun görülebilmesi imkanı tanımaktadır (Zink,Schmidt,1998,3, Öztemel,2001)). Özdeğerlendirme, işletmelerin;

- Faaliyetlerinin kuvvetli yönlerinin ve iyileştirmeye açık alanlarının tespit edilmesi

- Mükemmel sistemlerin nasıl olmasının gerektiğinin

- Mükemmellik seviyesinin tespit edilmesi

- Farklı işletmelere göre seviyesinin nasıl olduğu

- Hangi faaliyet alanlarında yoğunlaşması gerektiği gibi konularında bilgilenmesine olanak sağlar (Kalder,2003).

Öz değerlendirmede modellerinden modern anlamda verilen ilk kalite ödülü, 1951'de Japonya'dan ortaya çıkan Deming Uygulama Ödülüdür (Deming Application Prize - DAP). 1987'de Malcolm Baldrige Ulusal Kalite Ödülü (Malcolm Baldrige National Quality Award - MBNQA) ve 1991 yılında Avrupa Kalite Yönetim Vakfı (European Foundation Quality Management-EFQM) tarafindan verilen Avrupa Kalite Ödülü (European Quality Award - EQA) uygulamada en fazla faydalanılan modellere verilen ödüllerden birkaçıdır Hughes; Halsall, 2002). Türkiye'de ise genellikle uygulanan kalite modeli, EFQM Mükemmellik Modelidir (Kömürcü,2006). 


\section{EFQM MÜKEMMELLİK MODELİ}

Sürekli değiş̧en piyasa şartları ve artan rekabet, varlığını sürdürmek veya kendini geliştirmek isteyen firmaları farklı arayışlara itmektedir. Avrupa Kalite Yönetimi Vakfı bu amaca hizmet etmek için "EFQM Mükemmellik Modeli”ni geliştirmiştir. Modelin kurucusu Avrupa Kalite Yönetimi Vakfi (EFQM- European Foundation for Quality Management)'dır. Türkiye'de ise bu Türkiye Kalite Derneği (KalDer) tarafından yönetilmektedir.

Avrupa Kalite Yönetimi Vakfı (EFQM) 1988 yılında, Avrupa'nın önde gelen 14 şirketi (Bosch, British Telekom, Bull, Ciba-Geigy, Dassault, Electrolux, Fiat, KLM, Nestle, Olivetti, Philips, Renault, Sulzer, Volkswagen) tarafından Avrupa'da "Sürdürülebilir Mükemmelliğin itici gücü olma" misyonu ve "Avrupalı kuruluşların mükemmelliğe eriştikleri bir dünya" vizyonu ile kurulmuş (Nabitz; Klazınga; Walburg, 2000, 192), üyelik sistemine dayanan ve kâr amac1 gütmeyen bir kuruluştur (Moeller, 2001, 45; www.efqm.org/en).

Bugün dünya çapında 38 ülkede 800 ' ün üzerinde üyesi bulunmaktadır. EFQM'in üyeleri; dünya genelinde tanınan ve başarılı markalardan oluşan şirketlerdir. EFQM bunun yanısıra Akademik enstitüleri, Araştırma Enstitüleri, Yönetim Komiteleri, Ulusal Ticari Geliştirme Birliği ve Ulusal Ortaklık Organizasyonlarını da içermektedir.

\subsection{EFQM Mükemmellik Modelinin Kapsamı ve Önemi}

Avrupa Kalite Ödülü için kullanılan EFQM Mükemmellik Modeli, kesin çizgilerle sınırlandırılmamıştır. Organizasyonların sürekli gelişmesini ve sonucunda mükemmelliği yakalamasını isteyen, değişik yaklaşımları kabul eden bir modeldir (Ulaş, 2002, 39).

EFQM Mükemmellik Modeli, firmalara mükemmellik seviyesinin neresinde olduklarını gösteren, eksikliklerini belirlemelerine yardımcı olan ve bu eksikliklerin giderilmesi için uygun çözümler önererek gelişime teşvik eden bir araçtır. Avrupa Kalite Ödülü temasını benimseyen kuruluşlar için 1992 yılında modelin taslağı ortaya konulmuştur. Günümüzde model, hem ulusal hem de bölgesel olarak Avrupa'da birçok alanda geniş çapta kullanılmakta ve kalite ödülleri için bir temel oluşturmaktadır (Eskildsen and Dahlgaard, 2000, 1081-1082).

Modelin temeli müşteri memnuniyeti, çalışanların memnuniyeti ve toplumdaki etki olarak belirlenen bu üç faktörün bir araya gelerek oluşturacağı mükemmel iş çıktılarıdır. Tüm alanlarda süreklilik arz eden 
bir mükemmellik gerçekleştirmek için performans sonuçları üzerine kurulmuş olan EFQM Mükemmellik Modelinde, "Performans müşterilerin, çalışanların ve topluma yansıyan mükemmel sonuçların, politika ve stratejiler, çalışanlar, kaynaklar ve süreçlerin uygun bir liderlik anlayışıyla yönlendirilmesi ile sağlanabilir" ifadesine dayanır (Kaya; Üçgül; Aşkar vd., 2007, 274).

Mükemmellik modeli yalnızca bir teorik bir model olmayıp, uygulaması pratik ve kolay anlaşılır bir model olarak karşımıza çıkmaktadır. Temel faaliyet alanlarında ve belirlenen tüm süreçlerde gösterilen performans için ölçülebilen kayıtların bulunması gerekmektedir. $\mathrm{Bu}$ kayıtlar sadece işletmenin geçmiş finansal performansını gösteren kayıtlar ile sınırlı olmamalı, aynı zamanda müşterilerin tatmini ve bağl1lığı; çalışanların motivasyonu, yeterlilikleri ve toplumun tatminine ilişkin ölçülmüş kayıtlarıda içermelidir.

Modelin temeli toplam kalite yönetimini esas alır (Yılmaz, 2010, 65). $\mathrm{Bu}$ anlamda model, Avrupa'da toplam kalite yönetiminde en fazla başvuru alan model olarak karşımıza çıkmaktadır. EFQM Mükemmellik Modeli, toplam kalite yönetimine farklı bir bakış açısı getirerek sistemi bir bütün olarak ele alırken organizasyonel bilinci de harekete geçirmektedir. $\mathrm{Bu}$ sebeple, toplam kalite yönetimi ve EFQM Mükemmellik Modeli, işletmelerin değişen piyasa koşullarında hayatta kalabilmeleri için gerekli olan başarı sağlamalarında birbirini tamamlayan bir güç olmaktadır. (İnan; Yayla; Yıldız, 2010, 337).

EFQM Mükemmellik Modeli, uygulamayı gerçekleştiren tüm dünya işletmelerinden en iyi uygulama örneklerini göz önüne alarak girdileri toplamakta ve ihtiyaç olan tüm alanlarda modeli sürekli geliştirmektedir. Böylelikle, model tüm dünya ülkelerinde yer alan işletmelere aktif bir şekilde uyum sağlarken, dinamik yapısının olması ve yönetim konusundaki görüşleri sürekli güncelleyerek yansıtması sağlanmaktadır (Basım ve Şeşen, 2007, 203). Model, bu sebeple 1997, 1999, 2003 ve 2010 yılları olmak üzere şu ana kadar dört kez güncellenmiş, gelen geri dönüşler, yeni yaklaşımlar ve ihtiyaçlar çerçevesinde iyileştirilmiştir. 1999 yılında yapılan güncelleme sonunda model "EFQM Mükemmellik Modeli” ismini almıştır (KalDer, 2010, 30).

Modelin temelinde RADAR mantığı yer almaktadır. RADAR, herhangi bir kuruluşun performansını sistematik olarak değerlendirme olanağı sağlayan dinamik bir değerlendirme çerçevesi olan güçlü bir 
yönetim aracıdır. RADAR sayesinde yöneticilerin, kuruluşlarının hangi faaliyetlerinden, hangi sonuçları elde ettiğine dair neden-sonuç ilişkilerini anlaması sağlanır. RADAR, bir kuruluşun aşağıda belirtilen boyutları dikkate alması gerektiğini belirtir (Moeller; Breinlinger-O'Reilly; Esler, 2000, 255).

- Kuruluşun hedeflemiş olduğu sonuçları politika ve strateji oluşturma sürecinin bir parçası olarak ortaya koymak. Bu sonuçlar hem finansal hem de operasyonel açıdan kuruluşun göstermiş olduğu performansı ve paydaşlarının algılamalarını kapsamalıdır.

- Kuruluşun şu an mevcut olan ve/veya gelecekteki hedeflenen sonuçlara ulaşılabilmesi için birbiriyle bütünleşmiş, sağlam temelli yaklaşımları planlamak ve bu yaklaşımları geliştirmek.

- Yaklaşımların, tam olarak hayata geçirilmesini sağlamak üzere sistematik olarak yayılımını gerçekleştirmek.

- Elde edilen sonuçların izlenmesi ve analizi için, sürekli öğrenme faaliyeti içerisinde, uygulanan yaklaşımları değerlendirme ve sonuçlarını gözden geçirmek. Böylece kuvvetli yönlerinin ve iyileştirmeye açık alanlarının tespit edilerek, gereken yerlerde iyileştirme çalışmalarını gerçekleştirmek, planlamak ve uygulamak.

Tablo 1. RADAR açılımı ve Türkçe Karşılıkları

\begin{tabular}{|l|l|}
\hline Results & Sonuçlar \\
\hline Approach & Yaklaşım \\
\hline Deployment & Yayıllım \\
\hline Assessment & Değerlendirme \\
\hline Review & Gözden Geçirme \\
\hline
\end{tabular}

Model uygulanırken Radar Puanlama Matrisi kullanılmaktadır. Şekil.1.'de görüldügüü üzere RADAR Puanlama Matrisi aşağıda belirtilen bileşenlerden oluşmaktadır (Uygur ve Sümerli, 2013, 981; Moeller; Breinlinger-O'Reilly; Esler, 2000, 255; KalDer, 2010, 33):

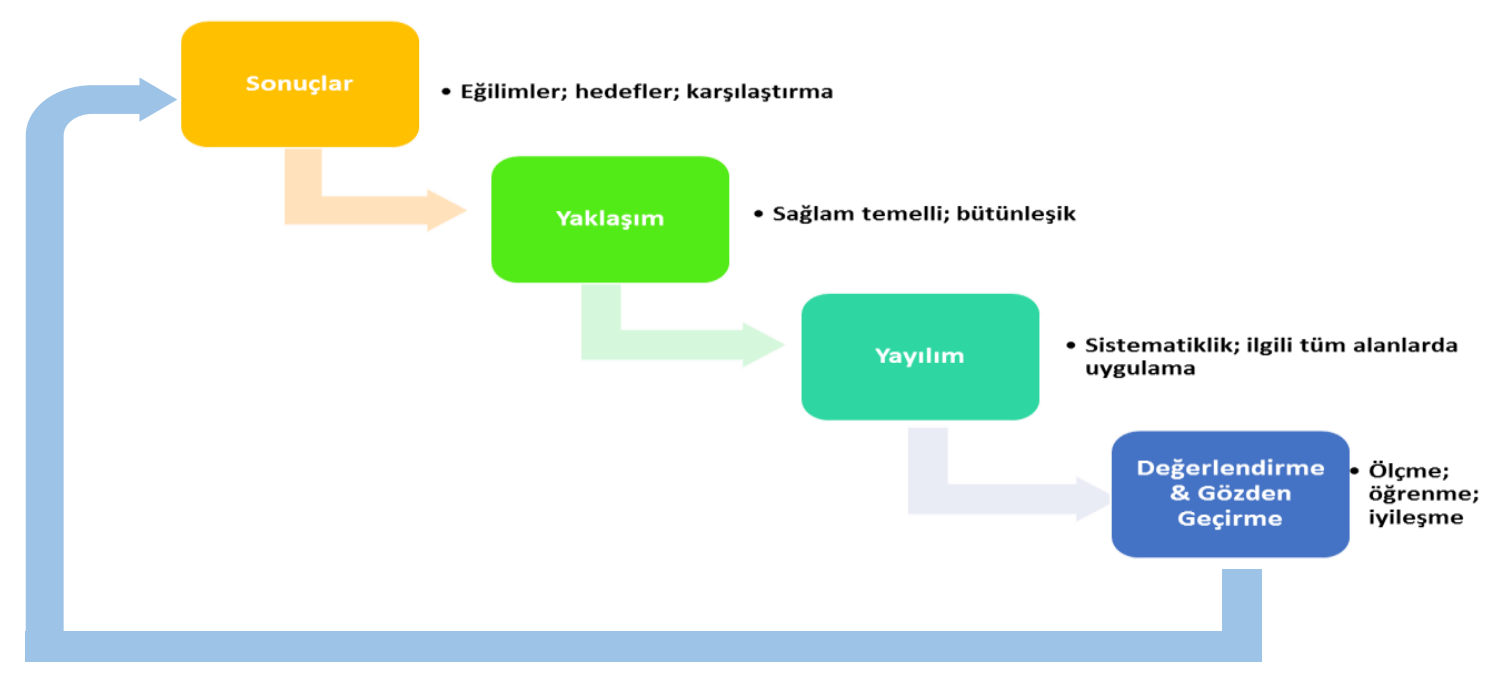


Şekil 1. Radar Sürekli Gelişim Döngüsü

Kaynak: Nabitz; Klazınga; Walburg, 2000, 194'den uyarlanmıştır.

RADAR mantığını oluşturan bu bileşenler şu şekilde açıklanabilir (Kalder, 2000, 17; EFQM, 2010, 14):

Sonuçlar: Kuruluşun neler elde ettiğini içerir. Mükemmelliğe erişmiş bir kuruluşta sonuçlar sürekli bir performansın varlığını göstermeli, kuruluşun hedefleri erişilebilir olmalı, başka kuruluşlar ile karşılaştırıldığında performansı yüksek olmalı ve tüm bu sonuçlar yaklaşımdan kaynaklanmalıdır. Bunlara ek olarak sonuçlar ilgili alan ve faaliyetleri de kapsamalıdır.

Yaklaşım: Kuruluşun ne yapmayı planladığını ve bunun nedenlerini içerir. Mükemmelliğe erişmiş bir kuruluşta yaklaşımın sağlam temelli olması; iyi tanımlanmış ve geliştirilmiş süreçlere sahip olması, paydaşların gereksinimlerine net olarak odaklanmış ve bütünleşmiş olması gerekir. Böylece kuruluşun bir yandan istenen politika ve stratejilere uyum sağlarken, diğer yandan da uygun olduğu ölçüde diğer yaklaşımlarla ilişkilendirilmiş olması beklenir.

Yayılım: Kuruluşun yaklaşımlarını hataya geçirebilmek için neler yaptığını içerir. Mükemmelliğe erişmiş bir kuruluşta yaklaşımın ilgili alanlarda sistematik bir biçimde uygulanması beklenir.

Değerlendirme ve Gözden Geçirme: Bu boyut, bir kuruluşun yaklaşımını ve yaklaşımının yayılımını değerlendirmek ve gözden geçirmek için neler yaptığını içerir. Mükemmelliğe erişmiş bir kuruluşta, yaklaşım ve yaklaşımın yayılımının düzenli olarak ölçülmesi, öğrenme faaliyetlerinin yapılması ve bunların sonucunda elde edilen bilgilerin iyileştirme çalışmalarının belirlenmesi, bu konudaki önceliklerin saptanması, planlanması ve uygulama amaciyla kullanılması beklenir.

RADAR Puanlama Matrisinin her bir bileșeni Şekil.2'deki EFQM Mükemmellik Modelinde yer alan her "Girdi" alt kriteri ile "Sonuçlar" boyutu da "Sonuç" alt kriterleri ile ilişkilendirilmelidir (Moeller, 2001, 46). Bir kuruluş RADAR'a göre puanlandığında, toplam puanı belirlemek üzere Model'in her bir kriteri için ayrı bir ağırlık katsayısı kullanılır. Bu ağırlıklar ilk olarak 1991 yılında belirlenmiştir (Moeller; Breinlinger-O'Reilly; Esler, 2000, 254) ve ağırlıklar EFQM tarafından düzenli olarak gözden geçirilmekte olup, 2010 yılından itibaren geçerli olan ağırlıklar (KalDer, 2010, 31) Şekil.2 üzerinde gösterilmiştir.

Şekil 2. Avrupa Kalite Vakfı Yönetimi Mükemmellik Modeli ve Ăğırlık Katsayıları

Kaynak: KalDer, 2010, 31; EFQM, 2010, 6. ve KalDer, 2010, 31; Kalder, 2015, 4

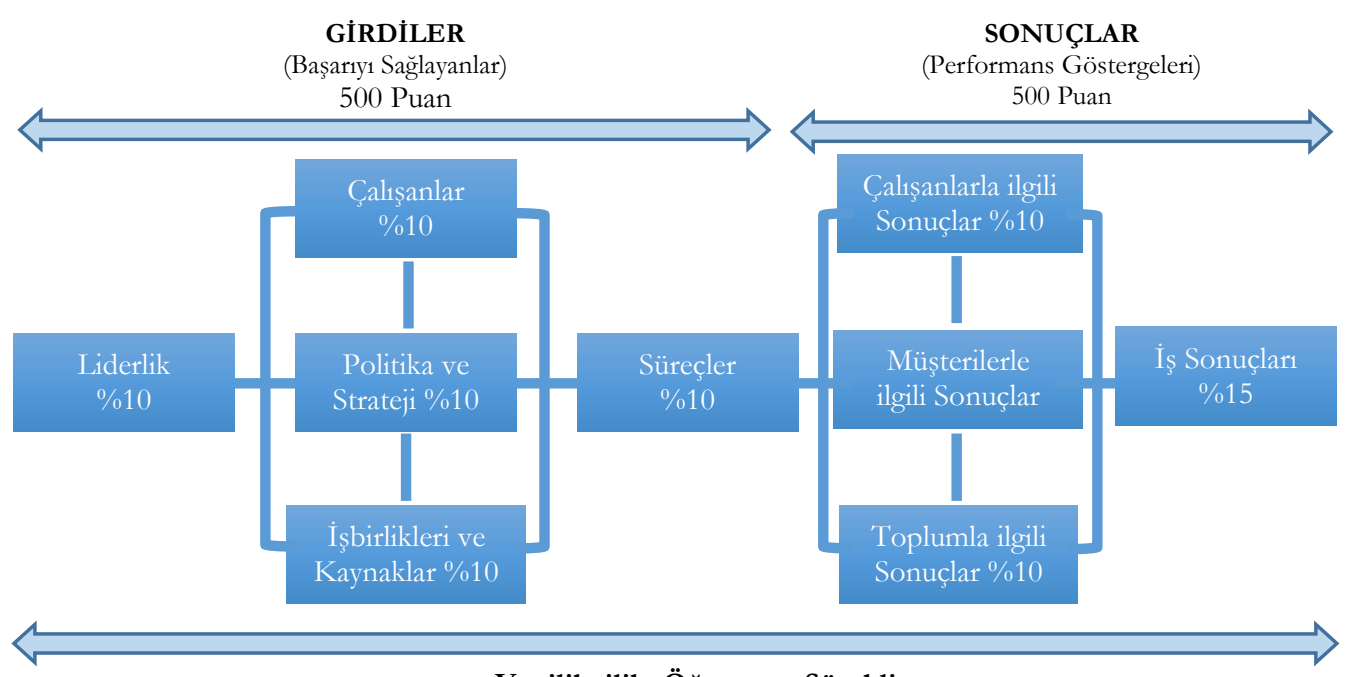

Yenilikçilik, Öğrenme, Sürekli 
Modelde kriterlerin ağırlık katsayıları alt kriterlere neredeyse eşit şekilde dağıtılmıştır. Puanlamanın ilk adımı RADAR değerlendirme tablosunu kullanarak her bir alt kriter için 100 üzerinden bir puan verilmektedir. $\mathrm{Bu}$ puanlama kriterle ilgili RADAR tablosunun boyutları ve unsurları dikkate alınarak yapılır (Nabitz; Klazınga; Walburg, 2000, 193- 194). 100 üzerinden verilen bu puanların puan özet tablosunda ilgili bölümlere Liderlik,

Çalışanlar, Politikalar ve Stratejiler, İşbirlikleri ve Kaynaklar, Süreçler, Çalışanlarla İlgili Sonuçlar, Müşterilerle İlgili Sonuçlar, Toplumla İlgili Sonuçlar, İş Sonuçları) yerleştirilmesi sonucunda toplamda 1000 puan üzerinden toplam puan hesaplanır (Eskildsen and Dahlgaard, 2000, 1082-1083).

Örneğin özdeğerlendirme ${ }^{1}$ amacıyla, mükemmellik modelini kullanan bir organizasyon mükemmellik kriterlerine bağlı olarak Şekil.2'deki modele uygun olarak değerlendirme sırasında şu şekilde bir puanlama yapabilir (Uygur ve Sümerli, 2013; Eskildsen and Dahlgaard, 2000, 1083; Moeller; Breinlinger-O’Reilly; Esler, 2000, 255; Kalder, 2015, 45).

\section{Girdi Kriterleri}

Tablo 2. Girdi Kriterleri ve Puanları

\begin{tabular}{|l|c|}
\hline Liderlik (\% 10) & 100 Puan \\
\hline Çalışanlar (\% 9) & 90 Puan \\
\hline Politika \& Strateji (\% 8) & 80 Puan \\
\hline İşbirlikleri \& Kaynaklar (\% 9) & 90 Puan \\
\hline Süreçler, Ürünler ve Hizmetler (\%14) & 140 Puan \\
\hline Toplam Girdi Kriterleri & 500 Puan \\
\hline
\end{tabular}

\section{$\underline{\text { Sonuç Kriterleri }}$}

Tablo 3. Girdi Kriterleri ve Puanları

\begin{tabular}{|l|c|}
\hline Müşterilerle İlgili Sonuçlar (\% 9) & 90 Puan \\
\hline Çalışanlarla İlgili Sonuçlar (\% 20) & 200 Puan \\
\hline Toplumla İlgili Sonuçlar (\% 6) & 60 Puan \\
\hline İş sonuçları (\%15) & 150 Puan \\
\hline Toplam Sonuç Kriterleri & 500 Puan \\
\hline
\end{tabular}

\subsection{EFQM Mükemmellik Modeli Kriterleri}

\footnotetext{
1 Özdeğerlendirme, bir kuruluşun faaliyetlerinin ve iş sonuçlarının, EFQM ükemmellik Modelini esas alan bir modelle kıyaslanarak; kapsamlı, sistematik ve düzenli olarak gözden geçirilme faaliyetidir. Özdeğerlendirme, şirketin kendi kendini değerlendirme sürecidir (Ulaş, 2002, 38).
} 
Günümüzün gelişen kalite ve yönetim yaklaşımları doğrultusunda kurumsal mükemmellik anlayışını benimseyen ülkeler bu çağdaş yaklaşımı çeşitli ulusal ve uluslararası modellerle teşvik etmektedirler. Japonya'da Deming (1951), ABD'de Malcolm Baldrige (1987) ve Avrupa'da EFQM modelleri (1992) en tanınmış ve yaygın kullanım alanı bulmuş kurumsal mükemmellik modelleridir (Nabitz; Klazınga; Walburg, 2000, 192). Ülkemizde de EFQM kriterlerini esas alan Mükemmellik Modeli benimsenmiştir.

EFQM Mükemmellik Modeli dokuz ana boyuta dayanır ve bu boyutlara kriter adı verilmektedir. Bu kriterler detaylandırılarak çeşitli sayıda alt kriterlerle desteklenmektedir. Şekil 2'de görüldüğü üzere modelin içeriği ve yapısına bakıldığında dokuz kriterden beşinin "girdi", dördünün ise "sonuç" kriterlerini oluşturduğu görülmektedir (Moeller; Breinlinger-O'Reilly; Esler, 2000, 254-255; Nabitz; Klazınga; Walburg, 2000, 192; Kalder, 2015, 4.).

Tablo.2'de gösterilen girdi kriterlerinde "nasıll", Tablo.3'te gösterilen sonuç kriterlerinde "ne elde ettik" sorularının yanıtları aranmaktadır. Bu açıdan, girdi kriterleri, kuruluşların yaptıkları faaliyetleri içerirken. sonuç kriterleri ise kuruluşların gerçekleştirebildiklerini gösterir. Sonuçlar girdilerden kaynaklanır ve girdiler, sonuçlardan alınan geri bildirim ile beslenir (KalDer, 2000, 15; Y1lmaz, 2010, 66).

EFQM Mükemmellik Modeli, yönetimin kalitesini ölçmeye yöneliktir. Ortaya konan yöntemlerin, hedefleri ne kadar iyileştirdiğine bakılır. Bu durumda PUKÖ döngüsünü esas alır (Deming,1982).

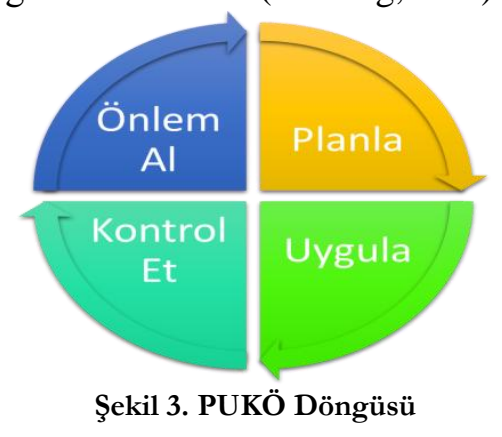

- Planla: Problemin tanımlanmas1, muhtemel sebeplerin belirlenmesi, veri toplama ve analiz etme, asıl sebeplerin ortaya konması, iyileştirme faaliyetlerinin tanımlanmasını içerir. Ne, ne zaman, nasıl, nerede, kim sorularına cevap verir. 
- Uygula: Planlanan iyileştirme faaliyetinin uygulanmasıdır.

- Kontrol Et: İyileştirme faaliyetlerinin uygunluğu ve doğruluğunun sonuçlarının kontrol edilmesidir.

- Önlem Al: Sürekliliğin sağlanması için standartlaştırma yapar ve çalışma kurallarını düzenler.

EFQM Mükemmellik Modeli'nin temeli olarak, her bir kavramın farklı kriterler ve alt kriterlerle doğrudan veya dolaylı çeşitli ilişkisi vardır. Model'de, 24'ü girdi ve 8'i sonuç olmak üzere toplam 32 alt kriter bulunmaktadır. Alt kriterler, değerlendirme sırasında cevaplandırılması gereken çeşitli sayıda sorulardan oluşmaktadır (Aksu, 2000, 130). Ayrıca her bir temel kavramın bir diğeri üzerinde de etkisi bulunmaktadır. Kriterler ve alt kriteri Tablo 4'de sunulmuştur. 
Tablo.4 EFQM Mükemmellik Modeli Kriterleri ve Alt Kriterleri

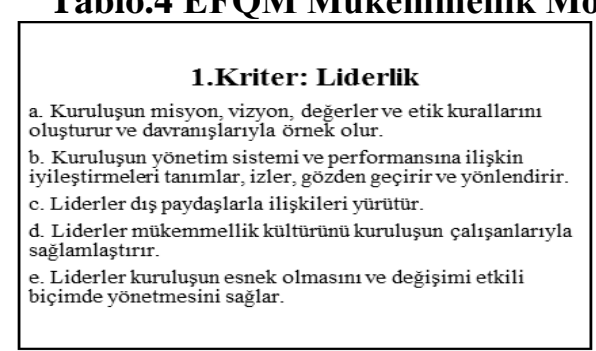

\section{Kriter: Çalışanlar}

a. Çalışanlara ilişskin planlar kuruluşun stratejisini destekler. b. Çalışanların bilgi birikimleri ve yetenekleri geliştirilir. c. Calışanların yön birliği ve katılımı sağlanır, çalışanlar yetkelendirilir

d. Çalışanlar kuruluşun tümünde etkili iletişim kurar. e. Çalışanlar takdir edilir, tanınırve gözetilir

\section{Kriter : Süreçler, Ürünler ve} Hizmetler

a. Süreçler paydaşlara
tasarlanır ve yönetilir.

b. Ürün ve hizmetler müșterilere en uygun değeri yaratmak amacryla geliștirilir.

c. Ürün ve hizmetler etkili bir biçimde tanıtılır ve pazarlanır.

d. Ürün ve hizmetler üretilir, sunulur ve yönetilir.

e. Müşteri ilişskileri yönetilir ve geliştirilir.

\section{Kriter: Çalışanlarla İlgili} Sonuçlar

a. Algilamalar

b. Performans Göstergeleri

\section{Kriter: Strateji}

Strateji, paydaşların ve dış çevrenin gereksinim ve beklentilerinin anlaşılmasını temel alı

b. Strateji, iç performans ve yeteneklerin anlaşılmasını temel

c. Strateji ve stratejiyi destekleyen politikalar oluşturulur, özden geçirilir ve güncellenir.

d. Strateji ve stratejiyi destekleyen politikalar duyurulur, uygulanir ve izlenir
4.Kriter: İșbirlikleri ve Kaynaklar

İ İ̧birliği yapılan kuruluşlar ve tedarikçiler sürdürülebilir yarar sağlama doğrultusunda yönetilir.

b. Finansal kaynaklar sürdürülebilir başarıyı güvence altın alacak biçimde yönetilir.

c. Binalar, donanım, malzemelerve doğal kaynaklar sürdürülebilir bir biçimde yönetilir.

d. Teknoloji, stratejinin yaşama geçirilmesini destekleyecek biçimde yönetilir.

e. Bilgive bilgi birikimi; etkili kararlar verilebilmesine destek olacak ve kurumsal yetenekleri geliştirecek biçimde yönetilir. Sonuçlar

Algilamalar

b. Performans Göstergeleri

8. Kriter: Toplumla İlgili Sonuçlar

a. Algilamalar

b. Performans Göstergeleri

\section{Kriter: İs Sonuçlar}

a. Temel Stratejik Çıktılar

b. Temel Performans Göstergeleri

Kaynak: Moeller, 2001, 49; Kalder, 2015, 4 'den uyarlanmıştır. 


\section{UYGULAMA}

Çalışmanın yapıldığı Kayseri ili Orta Anadolu bölgesinde sanayi ve ticaret açısından önemli bir yer edinmiştir. Kayseri'de 3 organize sanayi, 11 sanayi sitesi, 1 serbest bölge ve 1 teknopark mevcuttur. Kayıtlara göre Türkiye'deki sanayi işletmelerinin \%2'si Kayseri'de bulunmaktadır. Türkiye sanayi gelişmişlik sıralamasında 11. Sırada yer almaktadır. [81 il duurm raporu 2012]. Kayseri ilinde mobilya sektöründe yoğunlaşma olduğu için öncelikle mobilya sektöründeki firmalara sonrasında da diğer firmalara örnek olması amaçlanmıştır.

$\mathrm{Bu}$ çalışmada amaç Kayseri ilinde faaliyet gösteren bir mobilya üretim işletmesinin mükemmellik seviyesinin belirlenmesidir. $\mathrm{Bu}$ amaç doğrultusunda eksiklikler tespit edilerek, öneriler belirlenecek ve iyileştirme geliştirme faaliyetlerine katkıda bulunulması sağlanacaktır. Çalışmanın yapıldığı işletme 1986 yılından itibaren, güncel 542 Personeli ile üretim gerçekleştirmektedir.

Yapılan çalışma işletmenin tamamını kapsamakta, bu sebeple araştırma verileri toplanırken yapılan beyin firtınasına ve puanlamalara yönetim kurulu üyelerinin, müdürlerin ve belirlenen beyaz yaka çalışanların katılması sağlanmıştır.

\subsection{Araştırma Verilerin Toplanması}

Araştırma verilerine ulaşmak ve üst yöneticilerin konu hakkındaki düşüncelerini öğrenebilmek amacıyla veri toplama yöntemi olarak anket tekniğinden faydalanılmıştır

Anket formu tasarlanırken; EFQM Mükemmellik Modeli temel alınmıştır. Anket soruları hazırlanırken basit, net ve anlamı açık kelimeler kullanılmasına dikkat edilmiştir. Ayrıca konuya özgü bazı terimlerin daha iyi anlaşllabilmesi için konuyla ilgili örneklemeler ve bilgilendirmeler yapılmıştır. Anketler, kolayda örnekleme kullanılarak, katılımın artırılması amacıyla doğrudan işletmelerin ziyareti ile yüz yüze görüşme yöntemiyle uygulanmıştır.

EFQM mükemmellik modeli girdi ve sonuçlar ana ve alt kriterlerine göre 3 kişiden oluşan yönetim kurulu, 8 yönetici ve 15 beyaz yaka çalışan olmak üzere 3 farklı grup tarafından ayrı ayrı puanlanmıştır. Anket sonuçlarından elde edilen veriler, bilgisayar ortamına aktarılmıştır. Verilerin analizinde hazır bir istatistik paket programı kullanılmıştır. Güvenilirlik Cronbachs's Alfasına göre belirlenmiştir (0,882). Kriter 
ağırlıkları ile verilen puanlar çarpıldığında, ağırlıklandırılmış puanlara ulaşılmıştır.

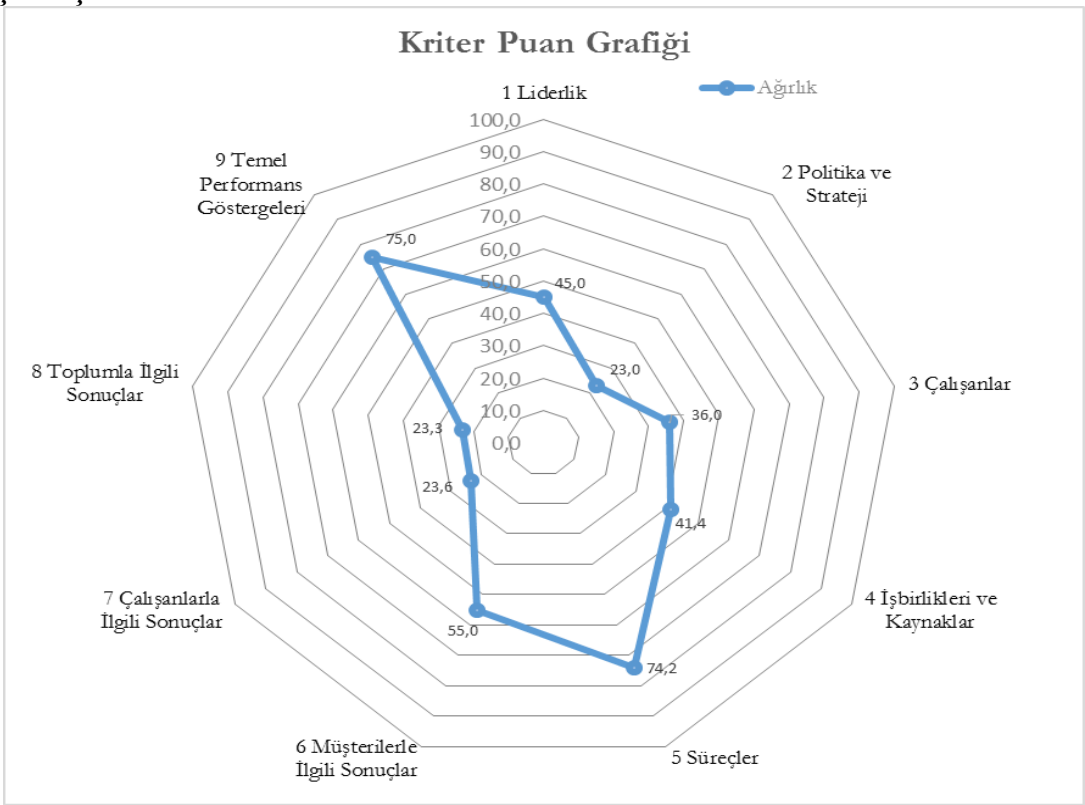

Şekil.4 EFQM Mükemmellik Modeli Sonuçları Radar Grafiği 
Tablo.5 EFQM Mükemmellik Modeli Kriter Puan Hesap Tablosu

\begin{tabular}{|c|c|c|c|c|c|c|c|c|c|c|c|c|c|c|c|c|c|c|c|c|c|c|c|c|c|c|}
\hline \multirow{3}{*}{$\begin{array}{l}\text { Kriter } \\
\text { Girdi/ } \\
\text { Çıktı } \\
\text { Kriter } \\
\text { No } \\
\text { Kriter } \\
\text { Puan } \\
\text { Hesap }\end{array}$} & \multicolumn{10}{|c|}{ GÍRDİLER } & \multicolumn{16}{|c|}{ SONUÇLAR } \\
\hline & \multicolumn{2}{|c|}{$\begin{array}{l}\text { Krit } \\
\text { er } 1\end{array}$} & \multicolumn{2}{|c|}{$\begin{array}{l}\text { Krit } \\
\text { er } 2\end{array}$} & \multicolumn{2}{|c|}{$\begin{array}{l}\text { Krit } \\
\text { er } 3\end{array}$} & \multicolumn{2}{|c|}{$\begin{array}{l}\text { Krit } \\
\text { er } 4\end{array}$} & \multicolumn{2}{|c|}{$\begin{array}{l}\text { Krit } \\
\text { er } 5\end{array}$} & \multicolumn{4}{|c|}{ Kriter 6} & \multicolumn{4}{|c|}{ Kriter 7} & \multicolumn{4}{|c|}{ Kriter 8} & \multicolumn{4}{|c|}{ Kriter 9} \\
\hline & $\begin{array}{l}\mathbf{A} \\
\mathbf{K}\end{array}$ & $\mathbf{P}$ & $\begin{array}{l}\mathbf{A} \\
\mathbf{K}\end{array}$ & $\mathbf{P}$ & $\begin{array}{l}\mathbf{A} \\
\mathbf{K}\end{array}$ & $\mathbf{P}$ & $\begin{array}{l}\mathbf{A} \\
\mathbf{K}\end{array}$ & $\mathbf{P}$ & $\begin{array}{l}\mathbf{A} \\
\mathbf{K}\end{array}$ & $\mathbf{P}$ & $\begin{array}{l}\mathbf{A} \\
\mathbf{K}\end{array}$ & $\mathbf{P}$ & $\mathbf{A}$ & $\begin{array}{l}\mathbf{A} \\
\mathbf{P}\end{array}$ & $\begin{array}{l}\mathbf{A} \\
\mathbf{K}\end{array}$ & $\mathbf{P}$ & $\mathbf{A}$ & $\begin{array}{l}\mathbf{A} \\
\mathbf{P}\end{array}$ & $\begin{array}{l}\mathbf{A} \\
\mathbf{K}\end{array}$ & $\mathbf{P}$ & $\mathbf{A}$ & $\begin{array}{l}\mathbf{A} \\
\mathbf{P}\end{array}$ & $\begin{array}{l}\mathbf{A} \\
\mathbf{K}\end{array}$ & $\mathbf{P}$ & $\mathbf{A}$ & $\begin{array}{l}\mathbf{A} \\
\mathbf{P}\end{array}$ \\
\hline $\begin{array}{l}\text { Alt } \\
\text { Kriter } \\
\text { Kodu }\end{array}$ & $\begin{array}{l}1 \\
\mathrm{a}\end{array}$ & $\begin{array}{l}4 \\
5\end{array}$ & $\begin{array}{l}2 \\
\mathrm{a}\end{array}$ & $\begin{array}{l}3 \\
0\end{array}$ & $\begin{array}{l}3 \\
\mathrm{a}\end{array}$ & $\begin{array}{l}3 \\
0\end{array}$ & $\begin{array}{l}4 \\
\mathrm{a}\end{array}$ & $\begin{array}{l}4 \\
0\end{array}$ & $\begin{array}{l}5 \\
\mathrm{a}\end{array}$ & $\begin{array}{l}4 \\
0\end{array}$ & $\begin{array}{l}6 \\
a\end{array}$ & $\begin{array}{l}2 \\
2 \\
0\end{array}$ & $\begin{array}{l}0 \\
7 \\
5\end{array}$ & $\begin{array}{l}1 \\
5\end{array}$ & $\begin{array}{l}7 \\
\mathrm{a}\end{array}$ & $\begin{array}{l}2 \\
5\end{array}$ & $\begin{array}{l}0 \\
7 \\
5\end{array}$ & $\begin{array}{l}1 \\
8, \\
7 \\
5\end{array}$ & $\begin{array}{l}8 \\
\mathrm{a}\end{array}$ & $\begin{array}{l}2 \\
0\end{array}$ & \begin{tabular}{l|}
0 \\
2 \\
5
\end{tabular} & 5 & $\begin{array}{l}9 \\
\mathrm{a}\end{array}$ & $\begin{array}{l}5 \\
5\end{array}$ & $\begin{array}{l}0 \\
5 \\
\end{array}$ & $\begin{array}{l}2 \\
7, \\
5\end{array}$ \\
\hline $\begin{array}{l}\text { Alt } \\
\text { Kriter } \\
\text { Kodu }\end{array}$ & $\begin{array}{l}1 \\
b\end{array}$ & $\begin{array}{l}4 \\
5\end{array}$ & $\begin{array}{l}2 \\
b\end{array}$ & $\begin{array}{l}3 \\
5\end{array}$ & $\begin{array}{l}3 \\
b\end{array}$ & $\begin{array}{l}2 \\
5\end{array}$ & $\begin{array}{l}4 \\
\mathrm{~b}\end{array}$ & $\begin{array}{l}5 \\
0\end{array}$ & $\begin{array}{l}5 \\
\mathrm{~b}\end{array}$ & $\begin{array}{l}5 \\
5\end{array}$ & $\begin{array}{l}6 \\
b\end{array}$ & \begin{tabular}{l|l}
5 \\
0 \\
0
\end{tabular} & $\begin{array}{l}0 \\
2 \\
5\end{array}$ & $\begin{array}{l}1 \\
2, \\
5\end{array}$ & $\begin{array}{l}7 \\
b\end{array}$ & $\begin{array}{l}3 \\
0\end{array}$ & $\begin{array}{l}0 \\
2 \\
5\end{array}$ & $\begin{array}{l}7 \\
5\end{array}$ & $\begin{array}{l}8 \\
b\end{array}$ & $\begin{array}{l}4 \\
5\end{array}$ & \begin{tabular}{l|}
0 \\
\\
7 \\
5
\end{tabular} & $\begin{array}{l}3 \\
3 \\
7 \\
5\end{array}$ & $\begin{array}{l}9 \\
b\end{array}$ & $\begin{array}{l}4 \\
5\end{array}$ & $\begin{array}{l}0 \\
5\end{array}$ & $\begin{array}{l}2 \\
2, \\
5\end{array}$ \\
\hline $\begin{array}{l}\text { Alt } \\
\text { Kriter } \\
\text { Kodu }\end{array}$ & $\begin{array}{l}1 \\
\mathrm{c}\end{array}$ & $\begin{array}{l}4 \\
5\end{array}$ & $\begin{array}{l}2 \\
\mathrm{c}\end{array}$ & $\begin{array}{l}2 \\
5\end{array}$ & $\begin{array}{l}3 \\
\mathrm{c}\end{array}$ & $\begin{array}{l}4 \\
0\end{array}$ & $\begin{array}{l}4 \\
\mathrm{c}\end{array}$ & $\begin{array}{l}4 \\
5\end{array}$ & $\begin{array}{l}5 \\
\mathrm{c}\end{array}$ & $\begin{array}{l}5 \\
0\end{array}$ & & & & & & & & & & & & & & & & \\
\hline $\begin{array}{l}\text { Alt } \\
\text { Kriter } \\
\text { Kodu }\end{array}$ & $\begin{array}{l}1 \\
d\end{array}$ & $\begin{array}{l}5 \\
5\end{array}$ & $\begin{array}{l}2 \\
d\end{array}$ & $\begin{array}{l}2 \\
5\end{array}$ & $\begin{array}{l}3 \\
d\end{array}$ & $\begin{array}{l}5 \\
5\end{array}$ & $\begin{array}{l}4 \\
\mathrm{~d}\end{array}$ & $\begin{array}{l}5 \\
0\end{array}$ & $\begin{array}{l}5 \\
\mathrm{~d}\end{array}$ & $\begin{array}{l}6 \\
5\end{array}$ & & & & & & & & & & & & & & & & \\
\hline $\begin{array}{l}\text { Alt } \\
\text { Kriter } \\
\text { Kodu }\end{array}$ & $\begin{array}{l}1 \\
\mathrm{e}\end{array}$ & $\begin{array}{l}3 \\
5\end{array}$ & & & $\begin{array}{l}3 \\
\mathrm{e}\end{array}$ & $\begin{array}{l}5 \\
0\end{array}$ & $\begin{array}{l}4 \\
\mathrm{e}\end{array}$ & $\begin{array}{l}4 \\
5\end{array}$ & $\begin{array}{l}5 \\
\mathrm{e}\end{array}$ & $\begin{array}{l}5 \\
5\end{array}$ & & & & & & & & & & & & & & & & \\
\hline $\begin{array}{l}\text { Alt } \\
\text { Kriter } \\
\text { ler } \\
\text { Topla } \\
\text { mı }\end{array}$ & & $\begin{array}{l}2 \\
2 \\
5\end{array}$ & & $\begin{array}{l}1 \\
1 \\
5\end{array}$ & & $\begin{array}{l}\mathbf{2} \\
\mathbf{0} \\
\mathbf{0}\end{array}$ & & $\begin{array}{l}\mathbf{2} \\
\mathbf{3} \\
\mathbf{0}\end{array}$ & & $\begin{array}{l}2 \\
6 \\
5\end{array}$ & & & & & & & & & & & & & & & & \\
\hline $\begin{array}{l}\text { Alt } \\
\text { Kriter } \\
\text { Sayısı } \\
\end{array}$ & & 5 & & 4 & & 5 & & 5 & & 5 & & & & & & & & & & & & & & & & \\
\hline $\begin{array}{l}\text { Ortala } \\
\text { ma } \\
\text { Kriter } \\
\text { Puanı }\end{array}$ & & $\begin{array}{c}4 \\
5, \\
0 \\
0\end{array}$ & & $\begin{array}{l}2 \\
8, \\
7 \\
5\end{array}$ & & $\begin{array}{l}4 \\
0, \\
0 \\
0\end{array}$ & & $\begin{array}{c}4 \\
6, \\
0 \\
0\end{array}$ & & $\begin{array}{c}5 \\
3, \\
0 \\
0\end{array}$ & & & & $\begin{array}{l}\mathbf{2} \\
\mathbf{7} \\
\mathbf{5} \\
\mathbf{0}\end{array}$ & & & & $\begin{array}{l}2 \\
6, \\
2 \\
5\end{array}$ & & & & $\begin{array}{l}3 \\
8, \\
7 \\
5\end{array}$ & & & & $\begin{array}{c}\mathbf{5} \\
\mathbf{0} \\
\mathbf{0} \\
\mathbf{0}\end{array}$ \\
\hline
\end{tabular}


Tablo.6 EFQM Mükemmellik Modeli Kriter Puanları Sonuç Tablosu

\begin{tabular}{|l|c|c|c|}
\hline \multicolumn{1}{|c|}{ Kriter } & Kriter Puanı & $\begin{array}{c}\text { Faktör } \\
\text { Ağırlığ́ }\end{array}$ & Ağırlıklı Puan \\
\hline 1 Liderlik & 45,00 & 1,0 & 45,0 \\
\hline 2 Politika ve Strateji & 28,75 & 0,8 & 23,0 \\
\hline 3 Çalışanlar & 40,00 & 0,9 & 36,0 \\
\hline 4 İşbirlikleri ve Kaynaklar & 46,00 & 0,9 & 41,4 \\
\hline 5 Süreçler & 53,00 & 1,4 & 74,2 \\
\hline 6 Müşterilerle İlgili Sonuçlar & 27,50 & 2,0 & 55,0 \\
\hline 7 Çalıssanlarla İlgili Sonuçlar & 26,25 & 0,9 & 23,6 \\
\hline 8 Toplumla İlgili Sonuçlar & 38,75 & 0,6 & 23,3 \\
\hline 9 Temel Performans Göstergeleri & 50,00 & 1,5 & 75,0 \\
\hline Toplam Puan & & & $\mathbf{3 9 6}$ \\
\hline
\end{tabular}

RADAR analizi sonucunda elde edilen ağırlık puanlarına göre iyileştirme yapılması gereken alanlar sıralanarak, önceliklendirilmiştir. Toplam 1000 puan üzerinden hesaplama yapılan RADAR çalışması sonunda işletmenin 396 puan aldığ 1 görülmüştür. Firma yönetim kurulu ile sonuçlar değerlendirilmiş ve firma için SWOT analizi yapılmasına karar verilmiştir.İşletmenin bir bütün olarak mevcut durumunun ve tecrübesinin incelenmesi, üstün ve zayıf yönlerinin tanımlanması ve bunların çevre şartlarıyla uyumlu hale getirilmesi süresine SWOT Analizi adı verilir (Dinçer, 1998,204). SWOT analizi işletmenin bugünkü güçlü ve zayıf yönlerinin ortaya çıkarılmasında, gelecekteki fırsat ve tehditlerin belirlenmesinde ve yeni stratejilerin oluşturulmasında işletmeye yardımcı olur (Albayrak, 2009,353). Güçlü yönler, zayıf yönler ve firsatlar ve tehditleri içeren SWOT analizi Tablo.7'de verilmiştir. 
Tablo.7 SWOT Analizi

\begin{tabular}{|c|c|}
\hline \multicolumn{2}{|c|}{ SWOT ANALIZİ } \\
\hline GÜÇLÜ YÖNLER & ZAYIF YÖNLER \\
\hline $\begin{array}{l}\text { - Yeni sistemlere hızlı adaptasyon } \\
\text { - Yönetimin projelere ve yeniliklere } \\
\text { desteği } \\
\text { - Ulusal ve Uluslararası Mobilya } \\
\text { Sektörü ve Fuarlar takibi } \\
\text { - Müşterilerin fazla olması } \\
\text { - Finansal kaynakların yeterli } \\
\text { seviyede olması } \\
\text { - Müşterilere yakınlık } \\
\text { - Tedarikçilere yakınlık } \\
\text { - Esnek İmalat } \\
\text { - İmalat için kullanılacak hammadde } \\
\text { ve yarı mamullerde dışa } \\
\text { bağımllığın az olması }\end{array}$ & $\begin{array}{l}\text { - İhracata yeterince ağırllk verilememesi } \\
\text { - İşlemlere/süreçlere yönelik yeterince } \\
\text { kontrollerin oluşturulmamış olması } \\
\text { - İnsan kaynakları yönetiminin yetersiz } \\
\text { olması } \\
\text { - İşçiliğin fazla olması ve Personel devir } \\
\text { hizının yüksek olması } \\
\text { - Bilgi teknolojileri yapisının ve } \\
\text { yönetiminin yetersiz olması } \\
\text { - Mevsimsel dalgalanma dolayı uzun } \\
\text { süreli plan yapilaması } \\
\text { - Stratejik planlama altyapisının olmaması } \\
\text { - Süreç Yönetim sisteminin olmaması } \\
\text { - Üretimde kullanilan hammadde } \\
\text { kaynaklarının kullanımına yönelik } \\
\text { verimliliğinin hesaplamasının yetersiz } \\
\text { olması } \\
\end{array}$ \\
\hline FIRSATLAR & TEF \\
\hline $\begin{array}{l}\text { - Mobilya değiştirme ihtiyacının } \\
\text { artması ve kullanıııdaki yenilik } \\
\text { isteği } \\
\text { - Küçük ölçekli firmaların ekonomik } \\
\text { dalgalanmadan dolayı uzun süre } \\
\text { tutunamamaları } \\
\text { - Uzman, eğitimli, genç nüfusun } \\
\text { artması ve yakın çevrede olması } \\
\text { - Benchmarking yapılabilecek } \\
\text { firmaların olması } \\
\text { - Moıbilya imalatında diğer } \\
\text { firmaların yeterince Gelişmiş } \\
\text { Argesinin, uzman işgücünün ve alt } \\
\text { yapısının Olmaması } \\
\text { - İhracattaki konum ve teşvikler }\end{array}$ & $\begin{array}{l}\text { - Yan sanayinin yeterince gelişmiş } \\
\text { olmaması } \\
\text { - Kolay kopyalanabilir ürünler ve kolay } \\
\text { sektöre girme } \\
\text { - Gelissmekte olan ülkelerin daha ucuza } \\
\text { ürün imal edip, sektöre girebilmesi } \\
\text { - Bireysel, özel taleplerin ve mevsimsel } \\
\text { dalgalanmaların olması } \\
\text { - Kur dalgalanmalarına bağlı alım satım } \\
\text { işlemlerinin etkilenmesi } \\
\text { - Kayıt dışı üretim }\end{array}$ \\
\hline
\end{tabular}

İşletmenin SWOT analizi sonrasında kuvvetli yönleri, iyileştirmeye açık alanları ve önerileri tespit edilmiş ve iyileştirme ve geliştirme projeleri belirlenmiştir. Belirlenen projeler ile firmanın EFQM 
seviyesinin artırılması hedeflenmiştir. Bu amaçla 2015-2017 yılları arasında aşağıda belirtilen sistemlerin kurulması önerilmiştir. Etki ve yapılabilirlik durumuna göre yapılması planlanan projeler aşağıda sıralanmıştır. Buna göre;

1. Yeni politikalar, stratejiler ve ve ilkeler hazırlanacaktır.

2. Yapılan SWOT analizinin sistematiği oluşturulacak ve her sene sonunda yeniden güncellenecektir.

3. Mali, finansal ve operasyonel süreçlerin kontrolünü sağlayacak altyapı oluşturulacak ve sürekliliği sağlanacaktır.

4. Çalışanlara yönelik yeni sistemler oluşturulacaktır. (ödüllendirme, öneri, hedef belirleme, yetkinlik gibi)

5. Mevcut süreçler gözden geçirilerek, yeni süreçler oluşturulacak ve süreç yönetim sistemi geliştirilecektir. (insan kaynakları, bilgi yönetimi, ürün tasarımı, stratejik planlama gibi)

6. Yeni yönetim sistemleri kurulacaktır. (Değişim, kıyaslama, stratejik yönetim, tedarik zinciri, bilgi güvenliği, alg1 yönetimi gibi)

7. Temel performans göstergeleri üzerine çalışmalar yapılacaktır. Şirket KPI (Key performance Indicators) ve PI (performance Indicators) rapor periyodu ve kontrolleri belirlenecektir.

\section{SONUÇ}

EFQM Mükemmellik Modeli'nin çıkış noktası, Avrupa'daki kuruluşların sürdürülebilir mükemmelliğini sağlayabilmek için itici güç olmaktır. Vizyonu ise; “Avrupa'daki kuruluşların mükemmel olduğu bir dünya"'dır. Bu sebeple geliştirilen model; müşteri tatmini, çalışanların tatmini ve toplum üzerindeki etki konularındaki başarının, politika ve stratejilerin, çalışanların, kaynakların ve süreçlerin uygun bir liderlik anlayışıla yönlendirilmesi ile sağlanabileceğini ve böylece iş sonuçlarında mükemmelliğe ulaşılabileceğini vurgulamaktadır.

Modelde, çalışanlar ve toplum gibi paydaşlar, işletmenin daha bütünsel bir resmini desteklemek suretiyle temsil edilir. Modelin güçlü yönlerinden birisi de finansal sonuçlarla ilgili olmasıdır. Modelin tamamı, modelin anlaşılmasında yardımcı olan kriterler arasındaki nedensel ilişkileri de ifade eden bir yapıya sahiptir. Nedensel ilişkiler, mantıklı ve sağlam görünür. Nedensel yapı, arzu edilen sonuçları (çalışan ve müşteri 
tatmini, toplumsal etki ve finansal sonuçlar) başarmak için gerekli olan yap1 ve alt yapıların geliştirilmesinden sorumlu olan liderlikle başlar.

EFQM Mükemmellik Modeli, kuruluşların mükemmellik yolunda hangi aşamaları geçtiğini kaydederek, yönetim sistemlerini geliştirmeleri konusunda onlara yardımcı olan uygulamalı bir araç niteliği taşır. Ayrıca kuruluşların kuvvetli yönlerini ve iyileştirmeye açık alanlarını görmelerini sağlayarak onları çözümler üretmeleri konusunda teşvik eder. EFQM denenmiş en iyi uygulamalarla ilgili girdileri toplayarak modeli güncelleştirir. Böylelikle, modelin dinamik olması, yönetim konusundaki güncel görüşleri yansıtması sağlanmış olur. Bir işletme faaliyet ve sonuç değerlendirmelerini, bu modeli esas alan diğer bir modelle karşılaştırarak, sistemli, bilimsel ve analitik düzeyde bilgi sağlamış olur.

Sistemin bütününü ele alan EFQM Mükemmelik modeli özdeğerlendirmeyi yaparken farkındalığında sağlanmasına yardımcı olur. Gerek çalışmanın yapıldığı alanda gerekse güncel metot ve yeniliklerle tanışma açısından bir farkındalık yaratır. İşte bu sebeple modeli uygulamaya geçebilmek birçok farklı çalışmayı da beraberinde getirmektedir. Kayseri'de mobilya sektöründe yapılan uygulamada çalışanların, müşteri ve tedarikçiler dahil tüm paydaşların, yöneticilerin sistemi bir bütün halinde düşünebilmelerinin yanında, güçlü ve zayıf yönlerini, tehditlerini ve firsatlarını görebilmelerine yardımcı olan SWOT analizi çalışması da yapılmıştır. Yapılan çalışmalar sonucunda iyileştirme, geliştirme alanları belirlenerek firmaya uzun vadede yol gösteren bir uygulama elde edilmiştir. Firma tarafından yapılacak iyileştirmeler sonucunda 2017 yılsonunda yeniden EFQM hesaplamas1 yapılarak firmada yapılan iyileşmenin EFQM skoruna yansıması izlenecektir.

$\mathrm{Bu}$ modelin hem çalışanlar hem de kuruluşlar üzerinde yararlı ve olumlu etkileri de göz önünde bulundurulursa daha sağlıklı değerlendirmeler yapmak mümkündür. Çalışanları mükemmellik kavramları çerçevesi içinde bilgilendirerek, bilinç düzeyini artırır. Ayrıca işletmelerin birimleri üzerinde incelemeler yaparak, etkin ve verimli uygulamaların ortaya çıkmasını sağlar ve bu doğrultuda mükemmel plan ve stratejilerin oluşturulmasının önünü açar. Böylece tüm birimler tarafindan benimsenen ortak bir dil, düşünce ve hareket tarzının oluşmasını gerçekleştirir. 


\section{KAYNAKÇA}

AKSU, AKIN. (2000). "Malcolm Baldrige Kalite Ödülü". Standart Dergisi, 39 (462), 128-135.

ALBAYRAK, B. (2009). Proje Yönetimi ve Analizi (1.

Baskı). Ankara: Nobel Yayın Dağıtım.

BASIM, H. NEJAT VE HARUN ŞEŞEN. (2007). "EFQM

Mükemmellik Modeli Uygulamalarının Çalışanların Tükenmişlikleri Üzerine Etkisi: Sağlık Sektöründe Bir Araştırma". İktisadi Ve İdari Bilimler Dergisi, 21(1), 201-213.

DEMING E., (1982), Quality, Productivity and Competitive Position, MIT, Center of Advence Engineering, Cambridge. MA.

DINÇER, Ö. (1998). Stratejik Yönetim ve İşletme Politikas1 (5. Bask1). İstanbul: Beta Basım Yayım Dağıtım.

EFQM, European Foundation for Quality Management, http://www.efqm.org/en. (01.05.2011).

EFQM. (2003). "The European Foundation for Quality Management". EFQM Publications.

EFQM. (2010). "EFQM Transition Guide: How to upgrade to the EFQM Excellence Model 2010". EFQM Publications.

ESKİLDSEN, J. K. AND J. J. DAHLGAARD. (2000). "A Causal Model for Employee Satisfaction”. The TQM Magazine, 11(8), 1081-1094

HUGHES, A., HALSALL, D.N. (2002) "Comparison of the 14 Deadly Diseases and the Business Excellence Model", Total Quality Management, 13, 2.

İNAN, A. TALAT, Y. YAYLA VE A. YILDIZ. (2010). "EFQM Mükemmellik Modeli ile İşletmelerin Temel Performans İncelenmesine İlişkin Bir Uygulama”. Mühendislik ve Fen Bilimleri Dergisi, Sigma 28, 335-345.

KAYA, S., Ö. ÜÇGÜL, Ö. D. AŞKAR VE RERHANI MAHNUT. (2007). "Konfeksiyon Sektörü için ISO 9000: 2000 ve EFQM Mükemmellik Modeli'nin Karşılaştırılması”. Ege Üniversitesi Tekstil ve Konfeksiyon Araştırma uygulama Merkezi, 17(4), 273-278.

KÖMÜRCÜ, N., (2006) "Sağlık Hizmetlerinde Kalite", Marmara Üniversitesi HYO.

MOELLER, J., J. BREINLINGGER-O'REILLY AND J. ELSER. (2000). "Quality Management in German Health Care- The 
EFQM Excellence Model". International Journal of Health Care Quality Assurance, 13(6), 254-258.

MOELLER, JOHANNES. (2001). "The EFQM Excellence Model. German Experiences with the EFQM Approach in Health Care". International Journal of Health Care, 13(1), 45-49.

NABİTZ, U., N. KLAZINGA AND J. WALBURG. (2000). "The EFQM Excellence Model: Europian and Dutch Experiences with the EFQM Approach in Health Care". International Journal of Health Care, 12(3), 191-201.

ÖZTEMEL, E.(2001) "Belediyelerde Toplam Kalite Yönetimi”, Değişim Yayınları, Adapazarı.

ULAŞ, S. (2002). "Toplam Kalite Yönetiminde İnsan

Kaynaklarının Rolü: Liderlik Üzerine Bir Uygulama”. Türkiye Cumhuriyeti Merkez Bankası İnsan Kaynakları Genel Müdürlüğü Uzmanlık Yeterlik Tezi, Ankara

UYGUR D.D.A., SÜMERLİ SARİGÜL S.,(2013) "Efqm Excellence Model", International Review of Management and Business Research, vol.2, pp.980-993.

Yilmaz, H. (2008). Vizyon, Misyon, Kariyer ve Daha Ötesi Stratejik Liderlik. Kum Saati Yayınları. İstanbul.

YILMAZ, HÜSEYINN. (2010). "Bilgi Yönetimi Sürecinde Performans Yönetim Modellerinin Uygulanması". Mehmet Akif Ersoy Üniversitesi Sosyal Bilimler Enstitüsü Dergisi, 2(2), 59-76.

ZINK, K., SCHMIDT, A. (1998) "Practice and Implementation of Self-Assessment", International Journal of Quality, 3, 2.

TÜRKIYE KALİTE DERNEĞİ. (2000). "EFQM Özdeğerlendirme Yöntemleri ve Uygulama Rehberi”. KalDer Yayınları, İstanbul.

TÜRKIYY KALİTE DERNEĞİ. (2003). "EFQM Mükemmellik Modeli El Kitabı" , Kamu ve Sivil Toplum İçin Mükemmellik Modeli El Kitabı, KalDer Yayınları, İstanbul.

TÜRKIYY KALITE DERNEĞİ. (2006). "Ortak Değerlendirme Çerçevesi (ODÇ) Kuruluşun Özdeğerlendirme Aracılı̆̆ıyla Geliştirilmesi”. KalDer Yayınları, İstanbul.

TÜRKIYY KALITE DERNEĞİ. (2010). "2010 Ulusal Kalite Ödülü Kitabı”. KalDer Yayınları, İstanbul. 
TÜRKIYE KALITTE DERNEĞİ. (2014). "2014 Türkiye Mükemmellik Ödülü Tanıtım Toplantısı. 22 OCAK 2014”. KalDer Yayınları, İstanbul. (http://www.tmoyk.org/dokumanlar/M\%C3\%BCkemmellik\%20\%C3\%96 $\mathrm{d} \% \mathrm{C} 3 \% \mathrm{BCl} \% \mathrm{C} 3 \% \mathrm{BC} \% 20 \mathrm{Bilgilendirme} \% 20$ Toplant $\% \mathrm{C} 4 \% \mathrm{~B} 1 \mathrm{~s} \% \mathrm{C} 4 \% \mathrm{~B}$ $1 \% 202014 \% 20$ Ocak.pdf.)

TÜRKIYE KALITE DERNEĞİ. (2015). "EFQM Mükemmellik Modeli Tanıtım Kitapçı̆̆ı’. KalDer Yayınları, İstanbul.

2010 Ulusal Kalite Ödülü Kitabı (2010). KalDer Yayınları, İstanbul.

(http://www.tmoyk.org/dokumanlar/modeltanitimkitabi.2015.pdf.)

KILIÇ, RECEP VE E. TURKER. (Mart 2005). "Süreç Yönetimi'nin EFQM Mükemmellik Modeli'ndeki Önemi (Eczacıbaşı Vitra A.Ş. Örneği)". Mevzuat Dergisi, 8(87). http://www.mevzuatdergisi.com/ (01.04.2011). 